How to Cite

Fatmawati, F., Yuliara, I. M., Riandhita, G., Kelo, F. J., Vellicia, A., \& Reswari, L. A. (2019). Tsunami level disaster based on simulation scenario of earthquake modeling and seismicity in South Bali 2010-2018. International Journal of Physics \&

Mathematics, 2(1), 36-41. https://doi.org/10.31295/ijpm.v2n1.88

\title{
Tsunami Level Disaster Based on Simulation Scenario of Earthquake Modeling and Seismicity in South Bali 2010-2018
}

\author{
Fatmawati \\ Udayana University, Denpasar, Indonesia \\ Corresponding author email: fhatmawati3@gmail.com
}

I Made Yuliara

Udayana University, Denpasar, Indonesia

Ganis Riandhita

Udayana University, Denpasar, Indonesia

Febriyanti Jia Kelo

Udayana University, Denpasar, Indonesia

Audrey Vellicia

Udayana University, Denpasar, Indonesia

Lintang Ardhana Reswari

Udayana University, Denpasar, Indonesia

\begin{abstract}
Bali is one of the areas prone to earthquakes and tsunamis because it is located in the meeting area of two plates namely the Eurasian and Indo-Australian plates located in the south of Bali and a back-arc trust zone located in the north of Bali. Research has been carried out on tsunami hazard level analysis based on scenario modeling and earthquake seismicity in southern Bali. This study uses earthquake data in January 2010 - July 2018. Tsunami prone areas in southern Bali are Klungkung district, Nusa Penida, Kuta beach, Sanur beach, Tabanan and Gianyar districts. The research conducted aims to determine the level of tsunami hazard by looking at the tsunami run up and arrival time in the southern region of Bali. This simulation model uses 1427 data which is then processed using Generic Mapping Tools (GMT) software so that seismicity maps are obtained, and tsunami modeling uses the Tsunami Observation and Simulation Terminal (TOAST) software. The results obtained from the tsunami modeling simulation in the form of altitude (run up) and tsunami wave arrival time (arrival time) which have an average value of 1,385 - 2,776 meters with an arrival time of 20-24 minutes. The tsunami hazard level is obtained in scenario A with a magnitude of 7.5 which has a maximum value of $<1$ meter (low) and scenario B with a magnitude of 7.8 has a maximum tsunami run-up value of 1-3 meters (medium) and in scenario $C$ with a magnitude 8.0 has a maximum runup of tsunami waves of $1-3$ meters (medium).
\end{abstract}

Keywords---Bali, earthquake, run up, seismicity, tsunami.

\section{Introduction}

In terms of tectonics, Bali Island is flanked by two earthquake sources, namely, in the north of Bali there is a backarc fault zone and to the south of Bali, there is a subduction zone. The rear fault zone extends from north Bali to Flores and the subduction zone is a meeting of two plates, namely the Indo-Australian plate (from south to north) and

ISSN 2632-9417

Received Jan 20, 2019 / Accepted Jun 18, 2019 / Published Jul 05, 2019 
the Eurasian plate (from north to south). Subduction zones that represent the main source area for tsunamis, can affect the southern part of the island of Bali (Hapsoro, 2010).

Based on records of tsunami history contained in the BMKG Tsunami Catalog, there have been several tsunamis that have struck plate subduction zones in the southern part of Bali. The Sumbawa tsunami occurred on August 19, 1977, with the epicenter at -11.085 South Latitude (LS), 118.464 East Longitude (BT), strength 8.0 Richter Scale (SR), and a depth of $10 \mathrm{~km}$. Tsunami waves that occur have a maximum height (run up) of 15 meters which killed 189 fatalities and caused a devastating impact on the surrounding area (BMKG, 2015). On July 3, 1994, there was a tsunami of Banyuwangi with the epicenter at $-10,477 \mathrm{LS}, 112,835 \mathrm{BT}$, strength $7.8 \mathrm{SR}$ and a depth of $18 \mathrm{~km}$. In this event, the maximum tsunami wave height (run up) was 13.90 meters which killed 215 people and had an impact on the surrounding area (BMKG, 2015).

Plate subduction zones in southern Banyuwangi are prone to tsunamis. This is due to the active earthquake energy from subduction in the south of Java (Sofyan et al., 2012). Sumbawa Island is influenced by two large and active tectonic systems, namely the zone of subduction of the Indo-Austalia plate against the Eurasian plate which moves actively to the north and back art thrusting found on the Flores sea which moves relative to the south. This condition causes the Sumbawa island to have a very intensive seismic activity (Yudhicara, 2013).

The condition of plate subduction zones in southern Bali has similarities with plate subduction zones in the south of Banyuwangi and Sumbawa where tsunami generator earthquakes have occurred. The similarity of tectonic elements provides an opportunity for earthquakes that have the potential to generate tsunamis in this region. Based on this, the southern part of the island of Bali is a region that has the potential to experience a tsunami hazard. As is known, southern Bali, especially on its beaches, there are many activities, facilities, and infrastructure supporting tourism. South Bali is the heart of tourism for Bali in particular and Indonesia in general. For this reason, as the first step in mitigation, one form of research that needs to be done is to analyze the tsunami hazard level. Tsunami hazard analysis is carried out through a tsunami modeling simulation scenario in several areas of southern Bali. The modeling scenario is based on the seismicity parameters of the earthquake that have ever been triggered by the IndoAustralian plate.

\section{Literature Review}

\section{Tectonic Conditions of the Island of Bali}

The island of Bali is one of the regions that have a high seismic level and is associated with subduction of the plate under Sunda Exposure and the activities of the continental continent of Australia and the continuation of the Sunda Arc line. With such conditions, it can result in the island of Bali shifting eastward and meeting the Banda Bow. The impact of the movement of these plates is the emergence of tectonic types which are characteristic of the subduction system, namely the sea trough, the Benioff zone, the outer arc basin, and the mountain path. Under the island of Bali, there is an earthquake zone with a depth of $100 \mathrm{~km}$ and its slope reaches $65^{\circ}$ with a range up to a depth of $650 \mathrm{~km}$ below the northern part of the island of Bali. On the Benioff pathway, igneous rocks are found along with the results of volcanic activity (volcanoes). The outer arc basin extends between the outer arc ridge and the volcanic arc (BMKG, 2015).

\section{Tsunami}

Tsunami waves are shallow water waves, where wavelengths can reach several hundred kilometers with small wave amplitude, which is \pm 1 meter in deep water. Shallow water waves have a propagation velocity that is directly proportional to the root depth of the ocean and is influenced by the Earth's gravitational force. The relationship between wave velocity and ocean depth is indicated by (Thornel et al., 1995; González et al., 2017; Rusman et al., 2017),

$$
v=\sqrt{g \cdot d}
$$

Which is:

$\mathrm{v}=$ speed $(\mathrm{m} / \mathrm{s})$

$\mathrm{g}=$ gravitational acceleration $(9.8 \mathrm{~m} / \mathrm{s} 2)$

$\mathrm{d}=\operatorname{depth}(\mathrm{m})$ 
In Equation above it can be seen that the greater the depth of the sea, the greater the velocity of the wave. The speed of propagation of a tsunami wave is $800 \mathrm{~km} / \mathrm{h}$ for deep water, $200 \mathrm{~km} / \mathrm{h}$ for middle water, and $25 \mathrm{~km} / \mathrm{h}$ when on land (Latief, 2000; Meza et al., 2017; 2018).

\section{Tsunami Process}

Earthquakes are one of the causes of tsunamis. Earthquakes can be caused by various sources, including volcanic eruptions (volcanic eruptions), meteor collisions, underground explosions (such as nuclear tests), and the movement of the earth's crust. Based on seismology, tectonic earthquakes can be explained by "Tectonic Layer Theory". This theory states that the outer layer of rock called lithosphere contains many plates. Under the lithosphere there is a layer called asthenosphere, this layer seems to lubricate the rock, so it is easy to move (Sugito, 2008).

Between these two layers, 3 things can happen, namely:

1) If the plate moves away from each other, then the magma from the bowels of the earth will come out to the surface of the earth. Magma that is already on the surface of the earth is called lava.

2) If the plates move against each other, then one of the plates will go up or down, or both up or down. This is the root of a mountain or valley.

3) Slabs move opposite each other, for example, one to the south and the other to the north.

\section{Tsunami Parameters}

Tsunami disasters are usually generated in deep waters then spread to more shallow waters. When it has entered shallow waters, the tsunami will then undergo a wave transformation, resulting in several parameters.

The parameters due to the transformation are:

1) Inundation, which is the area affected by the tsunami and measured from the coastline in meters or kilometers

2) Run up, which is the maximum tsunami height when reaching the furthest land the tsunami can reach.

3) Arrival time, which is the arrival time of the tsunami on the coastline

4) Travel time, which is the time needed to reach the coastline (Nakamura, 2006).

\section{Modeling and Seismicity Simulation}

Simulation is a technique that mimics operations or processes that occur in a system with the help of a computer device. Simulation is based on certain assumptions so that the system can be studied scientifically. In the simulation, a computer is used to study the system numerically, where data is collected to perform statistical estimation so that it gets the original characteristics of the system (Law, 1991).

\section{Tsunami Disaster Index}

The Disaster Threat Index is based on two main components, namely the possibility of a threat and the magnitude of the impact that has been recorded for a disaster. It can be said that this index is compiled based on data and historical records of events that have occurred in an area. In preparing disaster risk maps, these main components are mapped using GIS devices. Mapping will be carried out after all indicator data in each component has been obtained from a predetermined data source. The data obtained is then divided into 3 threat classes, namely low, medium and high.

\section{Methods}

\section{Location}

This research was conducted in the observation room on the 2nd floor of the Office of the Agency for Meteorology, Climatology and Geophysics Region III J1 Raya Tuban Badung Bali and the object of research examined in this study was the southern region of Bali with coordinates 8,382-10,314 LS and 114,693 - 115,616 BT which were regional analyzes affected areas include Klungkung district, Nusa Penida, Kuta beach, Sanur beach, Tabanan and Gianyar districts. 
Tools and materials

The software used in this study:

a) GMT (Generic Mapping Tools) is LINUX based graphics and mapping software but can be run on WINDOWS via CYGWIN software and GSVIEW display. This software is used for mapping seismicity data and historical data on tsunami earthquakes.

b) TOAST (Tsunami Observation and Simulation Terminal) a tool or GUI for tsunami simulation quickly and can be verified directly using a tide gauge or buoy. Tsunami simulation modeling based on the TsunAWI database. TsunAWI is a tsunami simulation model developed by the Alfred Wegener Institute (AWIGermany).

c) Microsoft Excel for further data processing.

\section{Research procedure}

The source of the tsunami was chosen based on the highest seismicity value in southern Bali for the location of the scenario. The scenario is among the potential tsunami earthquakes that have occurred near the island of Bali, namely the 1994 Banyuwangi earthquake and the 1977 Sumbawa tsunami. Then the authors made 45 scenarios with a magnitude of 7.5 and 7.8 and 8.0. The scenario with a magnitude of 7.5 is given the initials scenario A. The scenario with magnitude 7.8 is given the initials scenario B. The scenario with magnitude 8.0 is given the initials scenario C. Each has 15 scenarios with different position coordinates and depths.

\section{Results}

On the distribution map of earthquake seismicity data that occurred in January 2010 - July 2018 a cross section was created to be able to see the distribution of earthquakes in an area and could be generated in the form of hypocenter earthquake depths in each area in the study area. And from these data parameter, data can be made with hypocenter in the southern region of Bali which is the location of the study. Using the terms of the tsunami, the earthquake is centered on the seabed and has a magnitude greater than 6.0 SR, a tsunami simulation is made with the TOAST software through determining the value of the run-up and the time of the tsunami that will occur.

In a previous study conducted by Rahman (2015), with the title "Regional tsunami block" which was processed with the TSUNAMI N2 Software, the value of run up and arrival time was also determined. However, in previous studies, the focus was more on each beach block in Bengkulu while this study focused on the southern regions of Bali.

In general, Kuta beach is an area prone to tsunamis. From the value of the magnitude scenario used as a simulation, namely 7.5 - 8.0 SR, Kuta beach has the highest run-up value compared to other regions. Kuta beach area has a very low value. The Tabanan regency area has a high run-up height when simulated. The estimated time of arrival of the tsunami for Tabanan district is quite long, which is 17-21 minutes. Because of the location of Tabanan regency, which is quite far from the source of the earthquake in the southern part of the island of Bali, the time needed by the tsunami wave to reach Tabanan regency is also relatively longer.

For the Nusa Penida area which is separate from the island of Bali, it has a high run-up value but not as much as the run-up produced by the Kuta beach area. The Nusa Penida area in the south affects the run-up height. The ocean that stretches between the earthquake source area and the Nusa Penida area, causes a significant buildup of sea water waves. However, the condition of the area like this also resulted in the estimated arrival time of sea water waves faster than some other regions. This is because there is no land that can block the propagation of sea waves. When averaged, the estimated arrival time of the tsunami waves to reach the Nusa Penida area is 19-24 minutes.

For other regions, such as Klungkung regency, Sanur and Gianyar beaches have a fairly low run-up compared to the Kuta area. This is caused by the location of the area which is quite far from the source of the earthquake. Just like the Kuta beach area, Sanur beach area is also in the Bali island basin. However, the existence of Sanur beach in the opposite area of Kuta beach can affect the high run-up that occurs in the area. The location of the subduction zone in the south of Bali which is more westward affects the run-up height that occurs in the affected areas.

Areas such as Klungkung district, Sanur and Gianyar beaches that are located in the eastern region of Bali island tend not to have a significant impact compared to the Kuta beach area and Tabanan district. This is due to the location of Klungkung regency, Sanur and Gianyar beach further from the source of the earthquake. The estimated tsunami arrival time for these three regions is also greater compared to Kuta and Tabanan districts. 
There was a difference in the run-up and arrival time values generated by each scenario in the affected area. The highest run-up value is in the affected areas of Kuta beach with a scenario of magnitude 8.0 SR and the lowest runup value is in the Klungkung regency with a magnitude 8.0 SR scenario. This means that the affected area that has the greatest potential to experience a tsunami is the Kuta coastal area if an earthquake measuring $7.5-8.0$ SR occurs in accordance with the scenario in this study.

The biggest value of the coefficient of determination is in the Gianyar affected area, namely $\mathrm{R} 2=0.8011$. The correlation coefficient, in this case, $\mathrm{R}=0.895$, which means that there is a correlation of $89.5 \%$ between the variables magnitude and run up. For other affected areas, the correlation coefficient value is above $70 \%$. One-way testing for positive $t$ produces a $t_{\text {count }}$ of 2.0068 for the Gianyar region. From the reading of the table at the significant level $\square=5 \%$ and the degrees of freedom $\mathrm{df}=3$, obtained the value $\mathrm{t}_{\text {table }}=1.6377$ It can be seen that $\mathrm{t}$ count $>\mathrm{t}$ table and this means there is or there is an influence variable magnitude (x) on the run-up (y) variable in Gianyar area with a significant level of 5\%. The t-test for other affected areas also produces tcount $>t$ table. So, in general, it is said that there is the influence of the magnitude (x) scenario variable on run-up (y). Judging from the correlation coefficient, the regression equation model for Gianyar, namely $\mathrm{y}=1.2879 \mathrm{x}-8.9673$ is a model that can or is best used to predict the influence of the magnitude scenario on tsunami wave run-up.

The correlation between scenario magnitude and time of arrival, the lowest value, namely $64.47 \%$ is in Gianyar and the highest is $90.98 \%$ in Klungkung district. From the t-test with a significant level of 5\% which is done for each affected area, it produces a tcount $>t$ table. This means that there is the influence of the magnitude $(x)$ scenario variable on the arrival time variable (y) in the affected area with a significant level of 5\%. So, in general, it can be said that there is an influence of the magnitude (x) scenario on arrival time (y). Judging from the correlation coefficient, the regression equation model for Klungkung, namely $y=11,579 x-69,263$ is a model that can or is best used to predict the influence of the tsunami wave magnitude arrival time scenario.

From the analysis of the tsunami disaster level in several ways above, it can be seen that, at some affected points in southern Bali it has a maximum run up and arrival time from the observation of scenario A, scenario B and scenario C. It is noted that in scenario $\mathrm{C}$ with magnitude $8.0 \mathrm{SR}$ gives a maximum run-up of tsunami waves of $1-3$ meters (medium) and arrival time of $16-19$ minutes. This means that in the $\mathrm{C}$ run up scenario it is very fast compared to scenario A which has a maximum run up the value of $<1$ meter (low) and scenario B which has a maximum tsunami run-up value of 1-3 meters (medium).

From the discussion above the southern region of Bali, including areas that are potentially prone to tsunamis. As is known, southern Bali, especially on its beaches, there are many activities, facilities, and infrastructure supporting tourism. South Bali is the heart of tourism for Bali in particular and Indonesia in general. Overall, this can occur because the bathymetry conditions of the southern part of Bali are relatively land so that the tsunami waves that occur due to earthquake activity in January 2010 - July 2018 get a considerable friction force from bathymetry.

\section{Conclusion}

In calculating the altitude (run up) the average maximum value obtained at several points of the affected area is 1.385 - 2.776 meters which are in scenario $C$ with a magnitude of $8.0 \mathrm{SR}$. In the arrival time calculation, the maximum value obtained in some points of the affected area is $20-24$ minutes after the earthquake occurs which is in scenario $\mathrm{C}$ with a magnitude of 8.0 SR.

The seismicity value of earthquakes increases every year, from the tsunami disaster level analysis, in southern Bali has a maximum value, namely in scenario $A$ with a magnitude of 7.5 which has a maximum value of $<1$ meter (low) and scenario B with a magnitude of 7.8 has a value tsunami run-up maximum is 1-3 meters (medium) and scenario $\mathrm{C}$ with magnitude 8.0 has a maximum run-up of tsunami waves 1-3 meters (medium). The average time of arrival is around 20-24 minutes. 


\section{References}

González, AED, Arauz, WMS, Gamez, MR, \& Alava, LAC (2017). Photovoltaic energy to face an earthquake. International Journal of Physical Sciences and Engineering, 1 (3), 1930. https://doi.org/10.21744/ijpse.v1i3.61

Hapsoro, B. (2010). Will Jakarta Become the Brussels of the East?. Jakarta Post.

Latief, H., Puspito, N. T., \& Imamura, F. (2000). Tsunami catalog and zones in Indonesia. Journal of Natural Disaster Science, 22(1), 25-43.

Law, J. (Ed.). (1991). A sociology of monsters: Essays on power, technology, and domination (No. 38). Routledge.

Meteorologi, B. (2015). Klimatologi dan Geofisika (BMKG), 2016. Analisis Cuaca pada saat Kejadian Hujan Lebat dan Banjir di wilayah Kota Bandung pada tanggal, 24.

Meza, A. K. T., Chavez, S. A. R., \& Cedeno, E. A. E. (2017). Social resilience : earthquake consequences to an intense. International Research Journal of Management, IT and Social Sciences, 4(1), 24-31.

Meza, A. K. T., Freyre, J. R. A., Cevallos, M. G. O., \& Pico, M. J. M. (2018). Autonomy, Good Humor and Support Networks, Potential of Community Resilience Intervention in People Victims of the Earthquake in the Calderón Parish. International Research Journal of Management, IT and Social Sciences, 5(1), 1-8.

Nakamura, H., Arakawa, K., Itakura, H., Kitabatake, A., Goto, Y., Toyota, T., ... \& Mizuno, K. (2006). Primary prevention of cardiovascular disease with pravastatin in Japan (MEGA Study): a prospective randomised controlled trial. The Lancet, 368(9542), 1155-1163. https://doi.org/10.1016/S0140-6736(06)69472-5

Rahman, M. S., Akhtar, N., Jamil, H. M., Banik, R. S., \& Asaduzzaman, S. M. (2015). TGF- $\beta$ /BMP signaling and other molecular events: regulation of osteoblastogenesis and bone formation. Bone research, 3, 15005.

Rusman, -, Rohman, A., \& Abdulhak, I. (2017). Curriculum development training improvement in the competence geological disaster mitigation community based. International Research Journal of Engineering, IT \& Scientific Research, 3(2), 19-33.

Sofyan, Y. (2012). Development of a new simple hydrostatic equilibrium model for sustainable evaluation in geothermal energy. Energy Procedia, 14, 205-210. https://doi.org/10.1016/j.egypro.2011.12.918

Sugito, T. (2000). U.S. Patent No. 6,099,515. Washington, DC: U.S. Patent and Trademark Office.

Thornel, P. 100 fibers, Amoco Performance Products. Inc., PO Box, 849.

Yudhicara, Y., Zaim, Y., Rizal, Y., Aswan, A., Triyono, R., \& Setiyono, U. (2013). Characteristics of Paleotsunami Sediments, A Case Study in Cilacap and Pangandaran Coastal Areas, Jawa, Indonesia. Indonesian Journal on Geoscience, 8(4), 163-175. 